\title{
CKB Positive
}

National Cancer Institute

\section{Source}

National Cancer Institute. CKB Positive. NCI Thesaurus. Code C163010.

An indication that CKB expression has been detected in a sample. 